
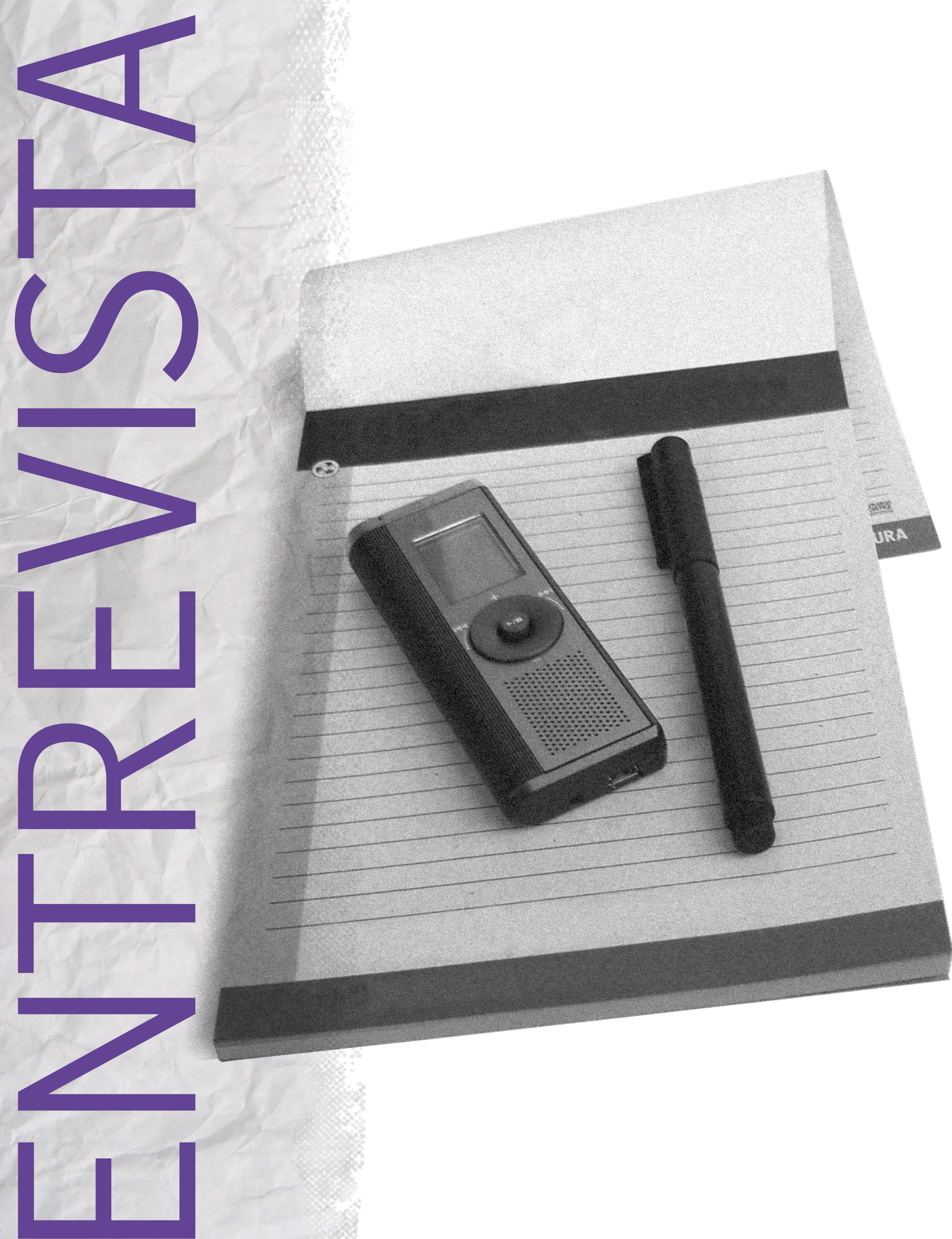


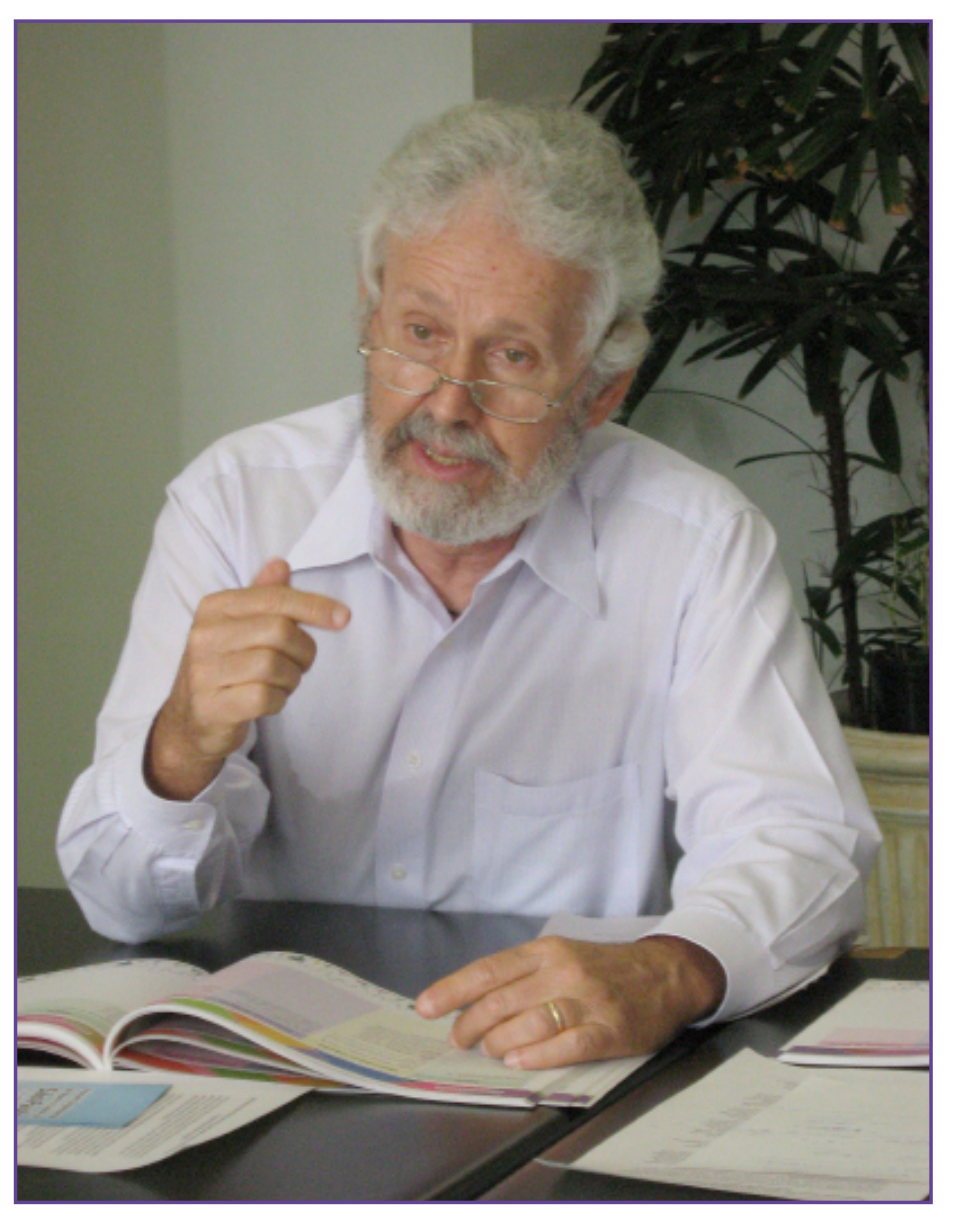

\section{Oded Grajew}

- Cofundador do Pensamento Nacional das Bases Empresariais (PNBE)

- Criador da Fundação Abring pelos Direitos da Criança e do Adolescente

- Cofundador e presidente emérito do Instituto Ethos de Empresas e Responsabilidade Social

Idealizador do Fórum Social Mundial e da Rede Nossa São Paulo

- E-mail: ograjew@isps.org.br

\section{A responsabilidade social na construção de um país justo e sustentável}

Social responsibility in building a fair and sustainable country

La responsabilidad social en la construcción de un país justo y sustentable

\section{Entrevistador}

Pedro Ulsen

- Doutorando e mestre em Ciências da Comunicação na Escola de Comunicações e Artes da Universidade de São Paulo (ECA-USP)

- Especialista em Jornalismo Literário e graduado em Jornalismo pela Universidade Estadual Paulista (Unesp)

•E-mail: pedroulsen@usp.br

Fonte da foto

Divulgação

Entrevista

Oded Grajew 
ANO 14 • NÚMERO $26 \cdot 1$ 프. SEM. 2017 • ORGANICOM

A RESPONSABILIDADE SOCIAL NA CONSTRUÇÃO DE UM PAÍS JUSTO E SUSTENTÁVEL

ascido em Tel Aviv, Israel, Oded Grajew mudou-se para o Brasil com a família quando tinha doze anos de idade.
Formou-se em Engenharia Elétrica pela Escola Politécnica da Universidade de São Paulo (Poli-USP) e é pós-graduado
em Administração de Empresas pela Fundação Getúlio Vargas (FGV).

Empresário, fundou em 1972 a Grow, dedicada a desenvolver jogos inteligentes para adultos e adolescentes, onde permaneceu até 1993. Nesse período já estava se dedicando ao terceiro setor e aos movimentos sociais, contribuindo com uma leitura de comando que a maioria dos militantes não conhecia por dentro. Oded atuou na idealização, liderança e gestão de organizações criadas para o desenvolvimento da sociedade.

Como empreendedor social, Oded Grajew tem revolucionado e aproximado a classe empresarial dos trabalhadores e engajando-a no desenvolvimento social. Foi um dos fundadores e o primeiro coordenador-geral do Pensamento Nacional das Bases Empresariais (PNBE), em 1989. Criou a Fundação Abrinq pelos Direitos da Criança e do Adolescente, organização que presidiu até 1998.

Idealizou o Fórum Social Mundial e é membro do seu Conselho Internacional. Em 1998, fundou o Instituto Ethos de Empresas e Responsabilidade Social, cuja missão é mobilizar, sensibilizar e ajudar as empresas a gerir seus negócios de forma socialmente responsável, tornando-as parceiras na construção de uma sociedade sustentável e justa.

Foi assessor especial do Presidente da República, quando articulou, junto com José Graziano e Frei Betto, o Programa Fome Zero. É membro do Conselho Deliberativo do Instituto Akatu pelo Consumo Consciente e integra o Conselho do Global Compact, das Nações Unidas.

Em 2007 idealizou a Rede Nossa São Paulo com a missão de mobilizar diversos segmentos da sociedade para, em parceria com instituições públicas e privadas, construir e se comprometer com uma agenda e um conjunto de metas, articular e promover ações, visando a uma cidade de São Paulo justa e sustentável.

ORGANICOM - No atual cenário econômico brasileiro, como convencer as empresas a investirem em ações direcionadas para o desenvolvimento social e a preservação ambiental?

Oded Grajew - De várias maneiras. Uma é fazendo pressão sobre o poder público para que se aprovem políticas públicas que façam com que as regras do mercado preservem o meio ambiente. Regras que promovam a sustentabilidade e a responsabilidade social empresarial, já que qualquer mercado opera com regras determinadas por políticas públicas. Então, primeiro agir sobre as políticas públicas para que haja regras nesse sentido, mas também que as leis sejam cumpridas. Além disso, agir sobre a imagem das empresas. As empresas se movem muito por imagem. Se uma empresa for realmente exemplar, socialmente responsável, que essa imagem seja comunicada, que seja valorizada. Isso ajuda as empresas a agir dessa forma diante do consumidor, diante da sociedade.

ORGANICOM - Como as organizações do terceiro setor têm se preparado para engajar as pessoas e ampliar o impacto de suas ações na sociedade? 
Oded Grajew - Na realidade, elas usam bastante a comunicação para isso. E a mobilização, hoje em dia, com a internet e as redes sociais, é mais democrática. Antes, você tinha que inserir ou cavar anúncios nos meios de comunicação. Hoje, você tem condições de agir nas redes sociais pela internet, mas aí você tem que fazer uma boa comunicação e ter conteúdo na comunicação. Porque assim você indica o que as pessoas podem fazer, o que devem apoiar, onde devem participar. Então, é o caso de juntar a excelência na comunicação, com conteúdo, para que as pessoas saibam exatamente com que se comprometeram e se mobilizem.

ORGANICOM - No artigo "Plano de metas contra a desigualdade", publicado no dia 17/1/2017 no jornal Folha de S.Paulo, você destacou a importância do plano de metas para a administração pública. De que forma você avalia que este plano pode reduzir a desigualdade social nas grandes cidades?

Oded Grajew - Neste exato momento em que nós estamos falando, elas enfrentam algumas dificuldades, até por causa da situação econômica, da crise econômica do país. Uma boa parte das organizações do terceiro setor vive de doações e contribuições financeiras do público em geral. E o momento econômico é bastante difícil. Algumas organizações têm apoio de empresas e estão fragilizadas pela situação econômica do país. Ao mesmo tempo, elas podem ganhar relevância por causa do momento político que o país atravessa. Como há muito descrédito nas instituições políticas, nos partidos políticos e nos políticos em geral, as pessoas que querem se engajar acham espaço nas organizações do terceiro setor.

ORGANICOM - Do ponto de vista global, de que forma você avalia a atual situação de desenvolvimento das organizações do terceiro setor no Brasil?

Oded Grajew - Eu acho que tem a ver com muita coisa. São vários fatores. Primeiro, uma questão da democracia. 0 país tem uma democracia bastante recente e bastante frágil, com falta de engajamento da sociedade. Nas democracias mais avançadas, as pessoas se preocupam mais com o coletivo, com a sociedade, e há um amadurecimento democrático em que diversos setores da sociedade se sentem mais responsáveis por seu país. E também o meio empresarial é menos concentrado, com mais diversidade, menor concentração e menos dependente do Estado. Para você mudar a situação da desigualdade em qualquer país, não basta ter ações empresariais. E não basta ter ações no terceiro setor, embora sejam importantes. 0

\section{As empresas se movem muito por imagem. Se uma empresa for realmente exemplar, socialmente responsável, que essa imagem seja comunicada, que seja valorizada.}


ANO 14 • NÚMERO 26 • 1은. 2017 • ORGANICOM

A RESPONSABILIDADE SOCIAL NA CONSTRUÇÃO DE UM PAÍS JUSTO E SUSTENTÁVEL

que faz os países serem mais ou menos iguais são as políticas públicas, a começar pela educação pública de qualidade para todos, o direito de igualdade e um sistema fiscal e tributário que faz com que quem tem mais pague mais, e quem tem menos pague menos. Há uma cultura que se desenvolveu no meio empresarial, de que é importante usufruir o máximo do Estado em beneficio próprio. A gente está vendo a Lava-Jato, um monstruoso esquema de apropriação do dinheiro público por um grupo de empresas, que ocorria há tanto tempo sem que houvesse uma voz no setor empresarial que se levantasse e contasse o que estava acontecendo e denunciasse. E também organizações empresariais bastante arcaicas que são os sindicatos, as federações, que vivem do Estado, vivem do imposto sindical, vivem de favores do Estado e não têm condições de confrontar o Estado, demandar políticas públicas para diminuir a desigualdade. E até uma baixa inteligência empresarial, porque uma sociedade menos desigual, de melhor qualidade de vida, seria melhor para os negócios, teria mais gente com recursos e mais consumidores. Existe uma visão muito estreita de boa parte das elites empresariais do País.

ORGANICOM - Porque, apesar de todos os esforços de movimentos sociais e organizações do terceiro setor, os empresários preocupados com desigualdade social ainda são minoria no Brasil?

Oded Grajew - Geralmente, tem muita gente que quer participar, quer contribuir, quer se sentir engajada, quer fazer alguma coisa. Isso é da natureza humana. Mas muitas vezes as pessoas não sabem como. Existe um grande número de pessoas interessadas, mas não sabem como participar. A comunicação para isso é fundamental, porque fornece uma orientação para as pessoas poderem participar, contribuir e sensibilizar as pessoas. Várias grandes campanhas de mobilização e sensibilização às vezes acontecem com grandes desastres, que são muito visíveis na mídia, e as pessoas colaboram, contribuem. Existe um desejo genuíno de as pessoas ajudarem e contribuírem. E a comunicação ajuda, porque você dá uma orientação de como elas podem ajudar. Você falou da comunicação comunitária. Muitas vezes as pessoas querem contribuir e ajudar na sua comunidade, na sua cidade, porque podem ver o resultado disso. Então, a comunicação comunitária também é muito importante.

ORGANICOM - Comoa comunicação e as relações públicas comunitárias podem contribuir estrategicamente para ampliar o engajamento da sociedade civil nas causas defendidas por aqueles que acreditam em um modelo de desenvolvimento mais justo e equilibrado?

Oded Grajew - 0 plano de metas de que estou falando foi o resultado de uma ação da sociedade civil, com propostas da Rede Nossa São Paulo e que depois se espalhou pelo país. Tratava-se de uma mudança na lei orgânica dos municípios, que obriga o prefeito a apresentar o plano de metas. 0 plano de metas hoje é obrigatório para as prefeituras de cinquenta cidades brasileiras, entre elas São Paulo, onde tudo começou. 0 plano de metas pode ter os objetivos mais diversos possíveis. 0 que foi colocado é que o maior objetivo teria que ser a redução da desigualdade, porque a desigualdade está na origem de todos os grandes problemas da sociedade, da humanidade e de qualquer cidade. Se você pegar o discurso de todos os grandes filósofos, lideranças religiosas, profetas de qualquer matiz, você vai ver que sua principal bandeira é a justiça social, a redução da desigualdade. Se você pegar hoje qualquer ranking no mundo, ranking social, ambiental, ético, econômico, em qualquer ranking mundial você sempre vê os países escandinavos lá em cima, alternando entre os primeiros lugares. Em qualquer ranking que você quiser. Por que isso? São os países considerados melhores, porque eles tomaram a decisão estratégica de que queriam ter uma sociedade menos desigual possível. E esse é o caminho que vai levá-los ao bem-estar. Tudo o que é montado lá - o sistema fiscal tributário, as políticas públicas - sempre privilegia a redução da desigualdade de uma sociedade razoavelmente menos desigual possível. E deu no que deu. Então, a desigualdade está na origem de todos os grandes problemas. Vou dar o exemplo de São Paulo. Um grande problema é a mobilidade. As pessoas moram em um lugar 
onde não têm trabalho e são obrigadas a pegar transporte coletivo para ir aos lugares mais ricos onde encontram trabalho. Não têm posto de saúde perto de casa ou não têm o equipamento público perto de casa. Isso é mal distribuído. Na região em que eles atuam não têm o que precisam. Além da questão da violência. Tanto é que em São Paulo, como eu coloquei no artigo, você tem na mesma cidade, dependendo do distrito em que você vive, uma diferença de expectativa de vida de 25 anos. Então o plano de metas pergunta: meta para quê? Sempre temos que nos perguntar qual é o sentido de tudo o que fazemos. E nesse artigo eu coloquei que o objetivo tem que ser um plano de metas que reduza a desigualdade na cidade de São Paulo. Se nós temos ótimos indicadores e presença de equipamentos públicos em algumas regiões, por que não se consegue fazer isso em outras regiões? Então, sempre, no sentido pessoal ou coletivo, a pergunta principal deveria ser: para quê? Primeiro você deve perguntar para que e ficar sempre atento ao que deseja alcançar em qualquer aspecto da vida pessoal, coletiva, organizacional. Essa pergunta deve preceder todas as outras.

ORGANICOM - No seu artigo "Universidade para quê?", publicado na Folha de S.Paulo no dia 7/1/2016, você defendeu que as universidades deveriam se tornar parceiras dos governantes eleitos para implementar novas ideias. Na sua avaliação, como essa interface com a academia pode ser aperfeiçoada na prática?

Oded Grajew - A academia tem uma responsabilidade grande. Ela forma as pessoas. Eu tenho falado que uma academia de excelência que não esteja baseada em valores é extremamente perigosa para a sociedade. Pessoas que cursaram grandes universidades, consideradas de qualidade no mundo, já fizeram barbaridades. Quanto mais você é preparado em um aspecto, mas despreparado na questão dos valores, você representa um perigo para a sociedade. Você tem essa competência para fazer as coisas boas e ruins. As grandes catástrofes na humanidade e as grandes barbaridades. Você pode ver a Lava-Jato no Brasil e todos os políticos corruptos. A grande maioria dessas pessoas fez universidade. As universidades que formaram essas pessoas deveriam se perguntar o que estão fazendo de errado. Eu não sei qual é a formação dele, mas acredito que o Marcelo Odebrecht deve ter feito universidade. 0 Antonio Palocci, o José Dirceu, o Eduardo Cunha, o José Sarney. Então, quando se fala que a educação de qualidade ou a educação para todos será o resgate para o Brasil, depende do tipo de educação. Se você continuar dando essa educação que foi dada para essas pessoas, isso vai ser um desastre, um perigo. As universidades devem se perguntar para que estão formando gente. De novo essa pergunta: para quê? Para que sejam bons

\section{As coisas acontecem quando a sociedade se junta. Ela ganha força política por juntar as pessoas. Nas organizações, muitas vezes, prevalece mais a competição do que a colaboração.}




\section{ANO 14 • NÚMERO 26 • 1ํㅗㄴ. 2017 - ORGANICOM}

A RESPONSABILIDADE SOCIAL NA CONSTRUÇÃO DE UM PAÍS JUSTO E SUSTENTÁVEL

engenheiros, bons administradores? Ou formar para que sejam bons cidadãos e, sendo bons cidadãos, exerçam determinadas atividades? Essa pergunta a universidade deve fazer. Estou falando das minhas frustrações com a academia. Isso é uma. A outra é que várias vezes eu tenho feito isso com diversas universidades. Eu costumo perguntar: considerando que vocês têm muito conhecimento acumulado em várias áreas, por que a academia não coloca isso à disposição da sociedade? Vou dar um exemplo. Em São Paulo temos muitas universidades consideradas de qualidade: a USP, a Unifesp, o Mackenzie. Na época da pré-eleição na cidade de São Paulo, falando com professores e reitores, perguntei por que eles não preparavam propostas para São Paulo que fossem colocadas a serviço dos candidatos. Não tive nenhum retorno. Diziam que... muito bem, que queriam fazer. Mas, nenhum retorno. Na época da crise da água, foi pedido e várias universidades estaduais se reuniram para preparar um plano para a manutenção de recursos hídricos para a cidade de São Paulo. De nada adiantou. Então, essa é a segunda frustração. A terceira é que a universidade é uma organização, e, quando falamos de responsabilidade social, que devem pautar as relações da empresa com todos os seus públicos internos e externos, com indicadores e processos, vários estímulos foram feitos em algumas universidades para que fossem socialmente responsáveis. Inclusive indicadores de como tratam seus funcionários e os professores, como tratam o meio ambiente, como tratam o lixo, como tratam os recursos naturais, como tratam a questão da transparência. Enfim, existem vários indicadores. E não conheço nenhuma universidade que tenha assumido de verdade uma gestão socialmente responsável. Elas podem citar algumas ações, que estão fazendo isso ou aquilo, mas não assumem uma gestão extremamente responsável, pautada por balanços e relatórios sociais, com acompanhamento dos indicadores, aplicação de propostas de melhorias e de pautas nas relações múltiplas das organizações. Isso não aconteceu até agora em nenhuma universidade que eu conheça, de assumir integralmente, de fato, uma gestão socialmente responsável. Você pode perguntar a qualquer um. Eles dizem que têm um projeto aqui, outro projeto lá. Mas não se sabe como é a diversidade no quadro de trabalho, a relação com os deficientes, a questão da diversidade de gênero e raça, quais são os benefícios, a assistência a seus funcionários, o que fazem com o lixo, como tratam a água, a luz natural, as emissões, o uso dos veículos, como tratam o espaço da universidade, a construção, a reforma.

ORGANICOM - De que forma você avalia que as pesquisas científicas podem contribuir para ampliar a consciência das pessoas sobre os impactos ambientais causados pelo homem?

Oded Grajew - Podiam levantar e mostrar os resultados, se inserir mais na sociedade. Fazer pesquisas, mobilização, debates, levantar a consciência, mostrar resultados.

ORGANICOM - Durante os anos 2000, o Fórum Social Mundial registrou ampla participação de movimentos sociais e personalidades brasileiras que acreditavam que outro mundo era possível. Por que, nos últimos anos, esse movimento vem perdendo força?

Oded Grajew - Na realidade, o Fórum Social Mundial se multiplicou em vários fóruns, espaços, fóruns locais, fóruns regionais, fóruns temáticos. Além de um evento anual, ele se multiplicou em vários tipos de eventos. Na questão da mídia, esta em geral sempre deu mais destaque ao Fórum Econômico, de Davos, do que ao Fórum Social Mundial. Mesmo na cobertura do Fórum Social em Porto Alegre, a mídia geralmente focava as questões folclóricas. Um rapaz que veio de Manaus e ficou tocando violão na beira do rio... Tínhamos vários eventos, debates com gente de qualidade, mas o foco da mídia era esse rapaz que tocou violão na beira do rio Guaíba. Nenhum jornalista foi realmente para assistir os debates. Tínhamos muito conteúdo, mas isso não aparecia na mídia, que encarava o evento do ponto de vista folclórico. Mas eu também acho que houve uma falha da nossa parte, de precisar trabalhar melhor a comunicação. Então, hoje, com muito mais redes sociais, a comunicação muito 
mais pulverizada, as pessoas acabam se comunicando e se mobilizando de outra forma. Tivemos vários fóruns. 0 último, em Montréal, no Canadá, em setembro do ano passado, teve cerca de quarenta mil pessoas. E tivemos fóruns a cada ano em Porto Alegre, fóruns menores, mais temáticos. Então, eu acho que também existe uma falha de comunicar melhor as coisas. E existe também um problema de parte das organizações da sociedade civil, que o fórum tentou corrigir, de trabalhar mais em conjunto, mais coletivamente. Muitas vezes essas organizações competem mais do que colaboram. E a ideia do fórum era juntar para que, de forma colaborativa, ganhando força política, possam agir. A força da sociedade civil é uma força que ocorre quando se junta. As coisas acontecem quando a sociedade se junta. A sociedade ganha força política por colaborar, juntar as pessoas, mas nas organizações, muitas vezes, prevalece mais a competição do que a colaboração.

ORGANICOM - Por que a sociedade brasileira tem tanta dificuldade em integrar os ensinamentos da Carta da Terra em ações práticas do cotidiano?

Oded Grajew -É uma sociedade que tem muita pobreza, muita gente vivendo para sobreviver, com demandas imediatas de sobrevivência, de pagar as contas, de comer, de ter uma casa, de ter o mínimo de condições materiais para viver dignamente. É a pobreza. Mesmo que nos últimos anos algumas camadas da população tenham ficado menos pobres, elas já voltaram, com a crise econômica, à condição inicial da pobreza, que faz com que as pessoas tenham que lutar para sobreviver. 0 segundo problema é o da educação, de informação, de conhecimento, de capacidade de absorver a comunicação. De elaborar as informações, de refletir, de pensar. E mesmo de entendimento das coisas. É um país com baixíssimo nível de educação e quem tem um pouco mais de dinheiro vai para a educação privada. E mesmo a educação privada, hoje, virou um grande negócio. Um país onde a educação e a saúde particular viraram grandes negócios tem algo de errado. São grandes negócios e muito lucrativos. Muitos milionários brasileiros estão lucrando com a saúde e a educação. Então, essa educação de baixa qualidade, baixíssima, com pouco acesso... Mesmo as universidades privadas viraram máquinas para preparar as pessoas para se darem melhor na vida, de qualquer maneira, a curto prazo, e isso dificulta bastante esse entendimento.

ORGANICOM - Qual é o balanço que você faz sobre as atividades desenvolvidas pelo Instituto Ethos, que está prestes a completar vinte anos? Quais foram as principais conquistas?

\section{Você pode gerar exemplaridades pelas suas ações, mas o impacto mesmo vem com as políticas públicas. 0 Ethos sempre trabalhou com a questão das políticas públicas.}


ANO 14 • NÚMERO 26 • 1ํSEM. 2017 • ORGANICOM

A RESPONSABILIDADE SOCIAL NA CONSTRUÇÃO DE UM PAÍS JUSTO E SUSTENTÁVEL

Oded Grajew - Eu conheço várias organizações empresariais que tentam promover a responsabilidade social empresarial em todo o mundo. Nenhuma delas se parece com o Ethos. Porque todas elas procuram promover a responsabilidade social nas empresas, fazer com que as empresas adotam critérios de gestão de responsabilidade social, mas nenhuma delas se preocupa e age para influenciar no sentido de que se tenha políticas públicas que favoreçam a responsabilidade social empresarial. 0 que ganha escala e tem impacto mesmo são as políticas públicas. 0 papel da sociedade civil, em geral, no terceiro setor, pode remediar situações de emergência, pode quebrar o galho no curto prazo de determinadas questões. Você pode, pelas suas ações, gerar exemplaridades, mas o impacto mesmo vem com as políticas públicas. Isso no Brasil, na China, nos Estados Unidos, na Europa, em qualquer lugar. O Ethos sempre trabalhou com a questão das políticas públicas. Vou lhe dar dois exemplos. Para diminuir o trabalho escravo no Brasil, o Ethos participou ativamente na criminalização do trabalho escravo e no processo que levou à elaboração da lista suja do trabalho escravo, que tem penalidades e consequências grandes para as empresas, e isso deu muito impacto. E dou mais um exemplo. Hoje você vê várias empresas envolvidas na Lava-Jato e vários empresários presos. Por que isso? Porque até três anos atrás, por incrível que pareça, não era crime no Brasil o empresário corromper agente público. 0 Ethos trabalhou bastante para que isso fosse caracterizado como crime. Há três ou quatro anos, você não podia prender ou processar o empresário que corrompia agentes públicos, por incrível que pareça. E o Ethos trabalhou bastante na mobilização para que isso se transformasse em crime, o que hoje faz com que você tenha muitos empresários e vários poderosos na cadeia. Uma coisa absolutamente inimaginável há alguns anos. Com medo dessa ação, várias empresas estão mudando. Mudando de postura, mudando de políticas. Além de tentar influenciar da melhor forma possível a legislação ambiental, participar ativamente como única entidade empresarial na aprovação da Lei da Ficha Limpa, que também foi um grande avanço e cassou muitos políticos com processos na Justiça. Isso nunca aconteceu antes. Então, na realidade, quando a gente começou o Ethos, nem se falava em responsabilidade social empresarial. A primeira atividade que fizemos foi um almoço com a imprensa para explicar do que a gente estava falando, que não era filantropia. Estávamos falando de responsabilidade social que pauta todas as atividades da empresa. Só para exemplificar a diferença entre filantropia e responsabilidade social empresarial: a empresa mais generosa do Brasil não investe em ações filantrópicas $1 \%$ do seu faturamento. Quando falamos em responsabilidade social empresarial, trata-se de $100 \%$ das atividades da empresa. É pular de 1\% para 100\%. Isso foi o que o Ethos implementou. Então, a cultura existe. Várias empresas avançaram. Falta muito, mas muitas políticas públicas foram elaboradas e implementadas graças à atuação do Ethos.

ORGANICOM - Ainda sobre o Ethos, quais são os próximos desafios para o instituto continuar com a missão de mobilizar, sensibilizar e ajudar as empresas a gerir seus negócios de forma socialmente responsável?

Oded Grajew - A missão do instituto foi bastante discutida entre nós que criamos o Ethos. E a missão do Ethos é tentar sensibilizar, mobilizar as empresas para que adotem uma gestão socialmente responsável e para que sejam parceiras na construção de um Brasil justo e sustentável. 0 maior desafio é essa segunda parte. Fazer com que as empresas sejam parte da mobilização, da sensibilização, para melhorar o país. Isso significa muita coisa, inclusive aperfeiçoar o nosso sistema democrático, fazer do Brasil uma democracia de verdade, não uma democracia de fachada, que atua em beneficio de poucos. Uma democracia que faça com que o país seja mais justo, com menos desigualdade, mais sustentável e que tenha um modelo sustentável e mais democrático.

ORGANICOM - Como as organizações do terceiro setor podem contribuir para reduzir os problemas sociais e diminuir os problemas de preservação do planeta? 


\section{ANO 14 • NÚMERO 26 • 1ํㅗㄴ. 2017 - ORGANICOM \\ A RESPONSABILIDADE SOCIAL NA CONSTRUÇÃO DE UM PAÍS JUSTO E SUSTENTÁVEL}

Oded Grajew - Divulgando e gerando consciência, divulgando os riscos da situação como está, porque a situação é preocupante. Muita gente não tem consciência disso, acha que o planeta é infinito, que a água é infinita, que a poluição não faz mal, que as florestas são infinitas, que a alimentação é infinita. Então, é preciso fazer alertas, levantar a consciência das pessoas para que, como cidadãos e como organizações, tentem mudar as coisas. Que isso se transforme em uma mobilização que mude as políticas públicas. Agora estão querendo avançar sobre as reservas indígenas, áreas de preservação ambiental. É necessário criar movimentos de rebeldia, de mobilização e de alerta. Com a comunicação, você pode promover o holocausto. Adolf Hitler já sabia da importância da comunicação. Você promove o holocausto, você promove matanças, você promove massacres, você promove ódio na torcida adversária. Mas você pode mobilizar amor e solidariedade. Então, a comunicação é fundamental. Ela pode promover grandes mobilizações. Apoderar-se dessa ferramenta é fundamental.

ORGANICOM - Em sua opinião, as ações de comunicação e relações públicas comunitárias praticadas por organizações do terceiro setor têm incentivado o debate sobre a importância de uma sociedade mais equilibrada?

Oded Grajew - Até agora, não. Em alguns momentos, sim. Eu acho que com a eleição do Collor, que veio depois do Sarney, com discurso de caça aos marajás, a sociedade se levantou, achando a importância da ética na política, de melhorar 0 país. E ele também fez um discurso populista de melhorar a vida dos pobres e se elegeu com pouca consistência. Outro momento foi a eleição do Lula. A sociedade se mobilizou, o elegeu porque achou que era o momento. As organizações sociais ajudaram bastante, porque era importante combater a pobreza, reduzir a desigualdade, acabar com a corrupção. A sociedade civil, as organizações, o Fórum Social Mundial, com o lema de que um outro mundo é possível, outro mundo é necessário, a sociedade civil teve um papel importante nisso. Mas eles foram eleitos com base no que a sociedade colocou. Também se conseguiu colocar na agenda mais ambiental com a votação que teve a Marina, também foi um momento em que a sociedade deu votação para determinados partidos. Mas é importante que a sociedade volte a acreditar que as mudanças vêm através das políticas públicas. Não é porque estão decepcionadas que devem desistir da política. Porque são as políticas públicas que mudam a sociedade e o país.

ORGANICOM - Qual é a importância do terceiro setor para organizar movimentos que promovam a cidadania em termos locais, regionais, nacionais e globais?

\section{A missão do Ethos é tentar mobilizar as empresas para que adotem uma gestão socialmente responsável e para que sejam parceiras na construção de um Brasil justo e sustentável.}


ANO 14 • NÚMERO 26 • 1은. 2017 • ORGANICOM

A RESPONSABILIDADE SOCIAL NA CONSTRUÇÃO DE UM PAÍS JUSTO E SUSTENTÁVEL

Oded Grajew - Fundamental, porque você mobiliza pessoas, você forma conceitos, forma as ideias, forma a cabeça das pessoas. Tudo o que fazemos na vida vem de um comando da nossa cabeça, do nosso coração, da nossa mente. A comunicação forma esses conceitos que levam à ação. É fundamental. Em todas as organizações com que temos falado, a comunicação está no eixo central. Então, ela é fundamental.

\section{ORGANICOM - Na sua avaliação, que nível de integração deve haver entre sustentabilidade e comunicação?}

Oded Grajew - Geralmente, se você quer fazer algum tipo de transformação, de mudança, você tem que pensar onde está o poder. Porque, inserindo ou mobilizando o poder para o seu lado, você consegue fazer as coisas. Ou, no máximo, neutralizar o poder que vem em sentido contrário. Então, mapear o poder é fundamental. 0 poder está na grande mídia, está nos jornalistas, está no meio econômico, está no setor cultural, nos ídolos esportivos. A mudança da Lei Orgânica dos Municípios foi uma grande mobilização que fizemos com atletas de renomes, que, como artistas, têm um grande poder de convencimento e mobilização. Então, mapear o poder para aquilo que você quer fazer e tentar fazer com que esse poder venha para o teu lado. Se é um poder que está de acordo com os seus pensamentos, seus valores, ele vem junto. Para aquele que é contrário, precisa montar uma estratégia para, no mínimo, neutralizar. Mas o mapeamento do poder é fundamental.

\section{ORGANICOM - A comunicação é estratégica para o desenvolvimento da sustentabilidade no terceiro setor?}

Oded Grajew - Todo mundo quer influenciar o poder público, inclusive as empresas. Então, é um embate para ver quem influencia mais, quem influencia menos. As políticas públicas, as pessoas precisam tomar consciência disso, são fruto pressão da sociedade. Na sociedade estou incluindo as empresas. Os políticos não tomam decisões sozinhos. Estão submetidos a pressões dos eleitores, pressão da mídia, pressão dos lobbies das empresas, pressão da mobilização da sociedade. Então, não sai da cabeça simplesmente dos políticos, porque os resultados finais são fruto de pressão. Nos países mais desenvolvidos, a mobilização da sociedade é geralmente mais profissionalizada, mais efetiva. Aqui, muitas vezes é mais amadora. Nós temos um problema no Brasil por a capital ficar em Brasília. No meu ponto de vista isso é muito ruim, porque dificulta o acesso, é caro ir até lá. Então, coloque o congresso, o poder executivo, a serviço de quem tem mais dinheiro, do poder econômico. Em outros países em que a capital é mais populosa, esta fica à mercê da população, da sociedade, é mais democrática, você não precisa de tanto dinheiro para chegar até ela. Nas democracias mais antigas, os sindicatos e outras organizações tiveram mais força. As regras lá são muito mais elaboradas. As regras do mercado no exterior constrangem muito mais para ter ética nos negócios do que aqui no Brasil. E, além disso, as consequências de não agir de acordo com essas regras são muito mais drásticas. Em empresas como a Volkswagen e outras, que se livraram da questão do controle da poluição, isso têm enormes consequências nos países com tradição democrática mais antiga. As regras são melhores, mais aperfeiçoadas, e as consequências são mais drásticas.

ORGANICOM - Além dos recursos de comunicação e relações públicas, que outras áreas dentro de uma empresa podem contribuir para a ampliação do debate sobre sustentabilidade e colaborar para uma nova consciência social?

Oded Grajew - A área de recursos humanos, junto com a comunidade interna e suas famílias, poderia ajudar bastante nisso. Mas isso depende muito da decisão da governança da empresa, da presidência da empresa. Primeiro, precisamos da decisão da empresa para mobilizar todas as suas relações. A área comercial tem muito a ver com isso, com fornecedores, com clientes. A área de recursos humanos também, pois trabalha com as pessoas e suas famílias. Mas isso tem que ser uma decisão estratégica da direção da empresa. 


\section{ANO 14 • NÚMERO 26 • 1ํSEM. 2017 - ORGANICOM \\ A RESPONSABILIDADE SOCIAL NA CONSTRUÇÃO DE UM PAÍS JUSTO E SUSTENTÁVEL}

ORGANICOM - Quais são os atuais desafios para as organizações do terceiro setor que atuam com a mobilização de empresas para a gestão socialmente responsável dos seus negócios?

Oded Grajew - Atuar mais conjuntamente para ganhar força de pressão e de convencimento. A força do terceiro setor é a força da união, da coletividade. É preciso colaborar mais, montar estratégias comuns, mais ainda nesse momento de fragilidade e de crise econômica, que coloca muitas organizações na fragilidade. Você não precisa fazer tudo, mas você pode ter alguém junto com você que faça aquilo que você não consegue fazer. É importante atuar mais coletivamente.

ORGANICOM - Como é possível avaliar o impacto das ações de engajamento e transformação social lideradas por empresários e movimentos sociais que têm atuado em benefício da sociedade?

Oded Grajew - Com indicadores. Não pode ser uma avaliação subjetiva. No ano passado, a ONU e todos os países assinaram compromissos com os "Objetivos do Desenvolvimento Sustentável". São dezessete objetivos bastante elaborados, bastante detalhados, onde cada um dos itens está relacionado com um indicador. 0 indicador é a hora da verdade. É como na saúde. 0 médico quer tratar um paciente e tem que olhar seus indicadores. Ele escolhe os indicadores que considera importantes para a sua saúde. Depois, ele faz o tratamento e mede o resultado do tratamento fazendo novos exames, vendo se os indicadores melhoraram ou pioraram, se aquele tratamento deu resultado. Então, ter indicador é fundamental. Se eu quero melhorar a educação na minha cidade, quais são os indicadores? Como está a evasão escolar? Na saúde, qual é a mortalidade infantil, qual é a mortalidade materna? Enfim, indicadores. Na Rede Nossa São Paulo, olhamos a cidade sempre com indicadores. Inclusive, indicadores da desigualdade. Primeiro precisamos definir o que nós queremos atingir, qual é o objetivo. E ter indicadores para saber se atingimos ou não atingimos.

\section{Tudo o que fazemos na vida vem de um comando da nossa cabeça, do nosso coração, da nossa mente. A comunicação forma} esses conceitos que levam à ação. Ela é fundamental. 